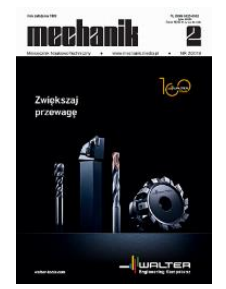

How to cite this article:

Authors: Paweł Bałon, Bartłomiej Kiełbasa, Edward Rejman, Robert Smusz, Janusz Szostak

Title of article: "Forming containers for PCM materials using a hydrotechnical method with an elastomer"

Mechanik, No. 2 (2019)

DOI: https://doi.org/10.17814/mechanik.2019.2.20

\title{
Forming containers for PCM materials using a hydrotechnical method with an elastomer
}

\author{
PAWEL BALON \\ BARTŁOMIEJ KIEŁBASA \\ EDWARD REJMAN \\ ROBERT SMUSZ \\ JANUSZ SZOSTAK*
}

Dr inż. Paweł Bałon, p.balon@szel-tech.pl -SZEL-TECH Szeliga Grzegorz, AGH w Krakowie, Polska

Mgr inż. Bartłomiej Kiełbasa, bartek.kielbasa@gmail.com - SZEL-TECH Szeliga Grzegorz;

Dr inż. Edward Rejman, erejman@prz.edu.pl - Politechnika Rzeszowska, Polska

Dr inż. Robert Smusz, robsmusz@gmail.com - Politechnika Rzeszowska, Polska

Dr inż. Janusz Szostak, szostak@agh.edu.pl - AGH w Krakowie, Polska

In this work, the authors present the method of forming by oil exerting pressure on the elastic punch forming the shape of a container for phase change material (PCM). Thanks to the use of two elastomer plates with a hardness of 65 and 80 Shore, the obtained part has mapped stiffeners in the middle and the appropriate depth of the bowl. This method is not widespread due to the precise design ensuring tightness of the load system of the formed blank. By reducing the tool costs, this method is used in particular in the case of unit production of prototype parts or small production series. The authors carried out tests of mechanical properties of the material, numerical analysis of feasibility with the FEM, real (workshop) trials after previous optimization by trial and error through structural changes of the tool. This allowed to obtain the best material drawing parameters for given boundary conditions. The research allowed to eliminate significant stresses and thinning in finished parts and corners of PCM containers.

KEYWORDS: stamping, forming, elastic punch, rubber forming

\section{Introduction}

Stamping processes with tools using elastomeric punches, especially rubber ones, are used primarily in unit and small-lot production. Complex shapes of manufactured products usually require expensive and specialized equipment. The advantage of using a flexible stamp is that a rigid die (steel or other material) is sufficient to make the stamping on the press, while the role of the stamp is played by a rubber or elastomeric spacer that adapts to the assumed shape. This allows to reduce tool costs by half and reduce the time to manufacture shaping elements.

Forming processing of sheets with the use of an elastic punch, also known as the universal punch method, offers many different forming possibilities. Flexible stamping dies supplement the forming methods with a steel rigid punch (or rigid die). The forming material can be rubber, elastomer, liquid (water or oil) or simultaneously elastomer and forming liquid. The use of hydrotechnical plastic forming (with the simultaneous use of an elastomer diaphragm and oil) is limited to forming bowl-type elements, while the method of pressing with the elastomer alone has no major restrictions. It should be mentioned that elastomer (especially rubber) can be used as an auxiliary element in the shaping process by other methods, e.g. as a pressure or filler preventing sheet cracking and folding. The main advantage of all elastomer molding methods is making the machining process independent of sheet thickness tolerance. It is also possible to shape sheets of variable thickness, so-called taylored blank method [7]. 


\section{Types of flexible punches}

Own work carried out on stamping with flexible stamp confirmed that rubber used as a stamp or universal matrix can be natural or synthetic. Its recommended strength properties are as follows: Shore hardness - from $60 \mathrm{HA}$ to $95 \mathrm{HA}$, tensile strength - from 6 to $20 \mathrm{MPa}$, acceptable elongation - from 350 to $650 \%$.

The amount of unit pressure in the rubber shaping process is selected depending on the material grade, sheet thickness and deformation factor (fig. 1). This value, as a function of deformation, also depends on the grade and hardness of the rubber.

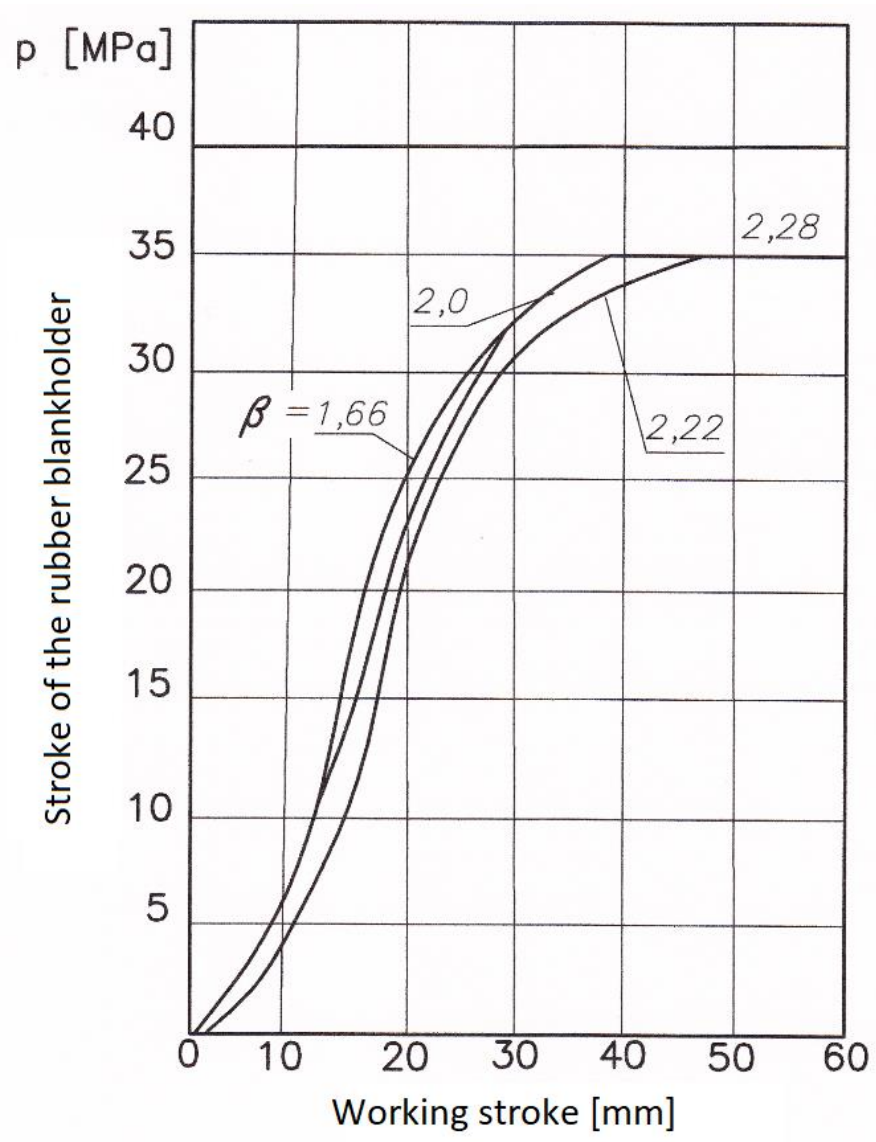

Fig. 1. Relation of unit pressure of rubber during elastic stamping as a function of stamp stroke (displacement) and deformation factor

When forming cylindrical parts, rubber pressures should be between 30 and $60 \mathrm{MPa}$. The thickness $H$ of the rubber cushion depends on the thickness of the shaped objects $h$ :

$$
H>50 \sqrt{h}
$$

The cushion, in the form of an elastomer or rubber, may consist of several individual layers, with a total thickness less than $50 \mathrm{~mm}$. The best effects of rubber pressing are obtained when forming parts that meet the geometric condition:

$$
l>70 g
$$

where: $l$ - the smallest length of the formed part, $g$ - sheet thickness (own research).

Elastomer molding creates extremely favorable flow conditions for the material, especially when deep drawn and using a steel die and flexible punch. For this reason, the most commonly used are concave dies, in which the rubber acts as a flexible punch. 


\section{Modeling of the pressing process by the finite element method}

In order to verify the presented forming method, the displacement values for the tested element were checked - using the finite element method (FEM) (fig. 2).

In order to assess the possibilities of making the tank with the use of a flexible stamp method, simulation of pressing with the use of FEM was carried out. A model was adopted, in which a flexible tool exerts pressure on elastic-plastic material. Numerical analysis was performed in the Pam-Stamp 2G software [6, 9]. Several material models and a dozen or so geometrical models of the tank were analyzed. The analysis used surfacetype elements, three- and four-node, based on the Belytschki-Tsaya model, based on homogeneous, coherent and reduced integration. The level of FEM mesh density was selected according to the criterion of the minimum value of matrix or punch radius [2]. The FEM model developed for forming with a flexible punch is shown in fig. 3.

In the forming operation - for both closing and pressing - the function of adjusting the mesh density level to the current local degree of material deformation was activated [1]. In practice, this saves time and, at the same time, the necessary accuracy of calculations by predicting the deformation caused by the movement of the punch.

The main difficulty of the FEM numerical simulation was the introduction of the elastomer material model, from which the punch was made. The adopted assumptions about the scope of Young's modulus and Poisson's number allowed to build a model with linear characteristics, which, however, turned out to be too simplistic. To more accurately describe the analyzed process, the Mooney-Rivlin solid model was used, in which material constants are determined by matching predicted stresses to equations from experimental data. The recommended material tests are: uniaxial stretching and compression, shear and planar compression [5].

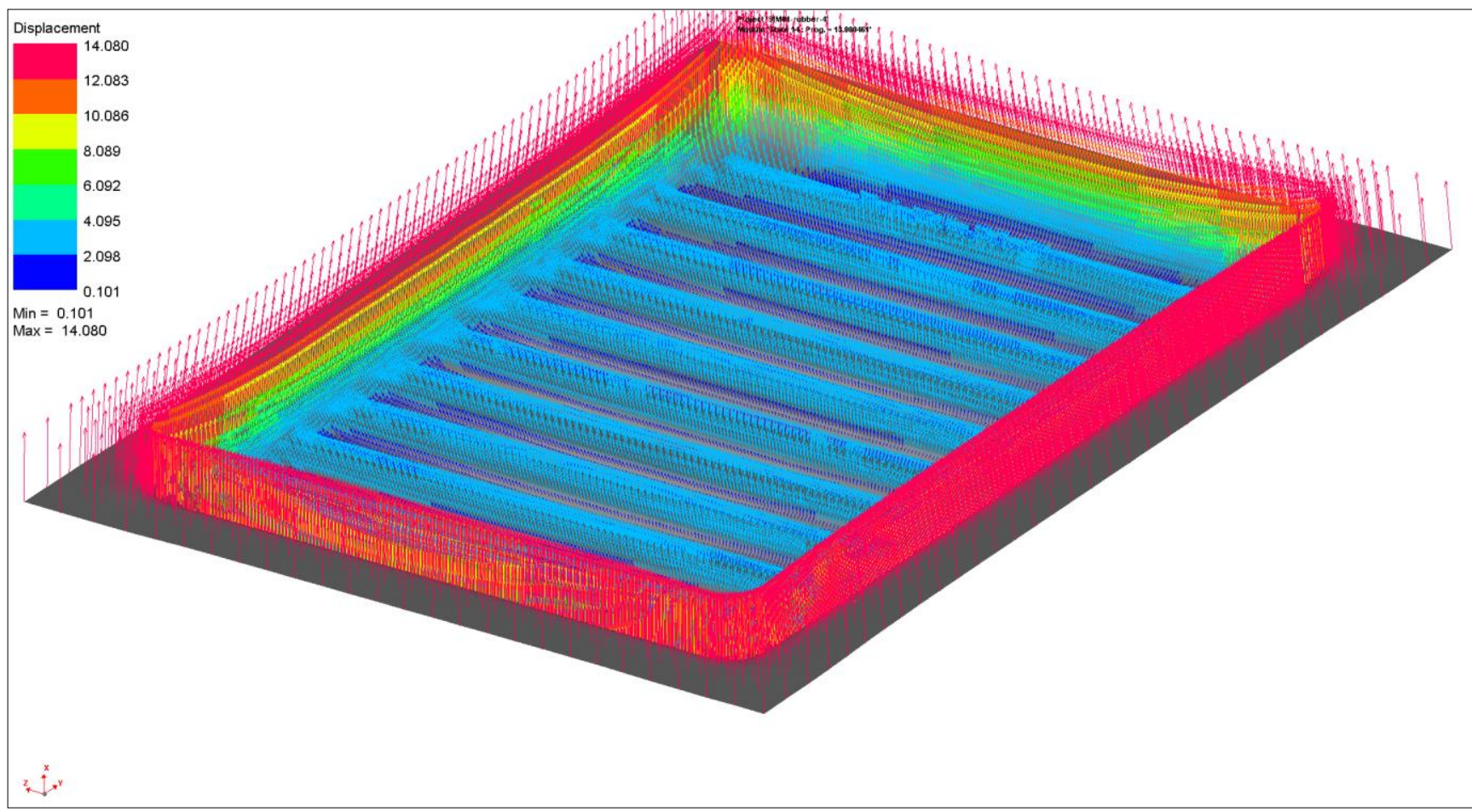

Fig. 2. Displacement values determined by FEM (vector) 


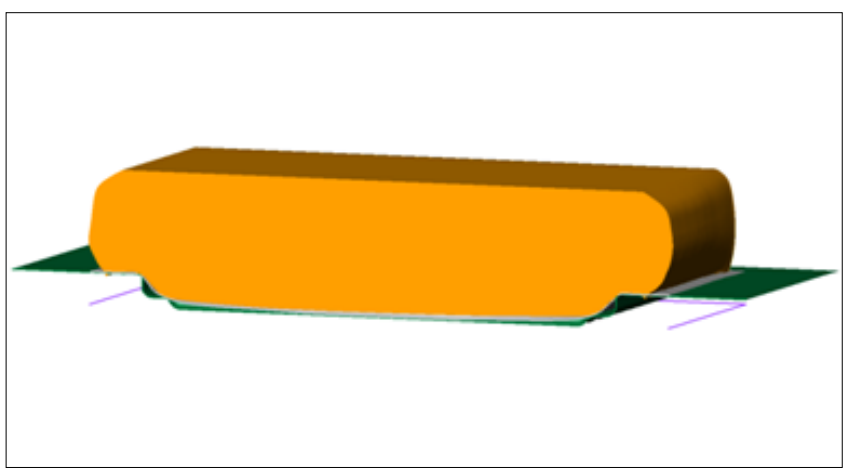

Fig. 3. FEM model for forming a part of the tank with a flexible punch

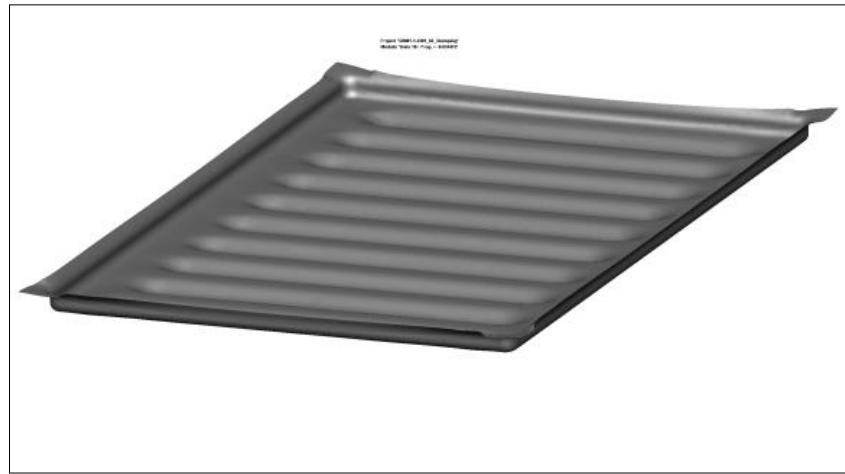

Fig. 4. Tank panels model obtained as a result of finite element molding simulation

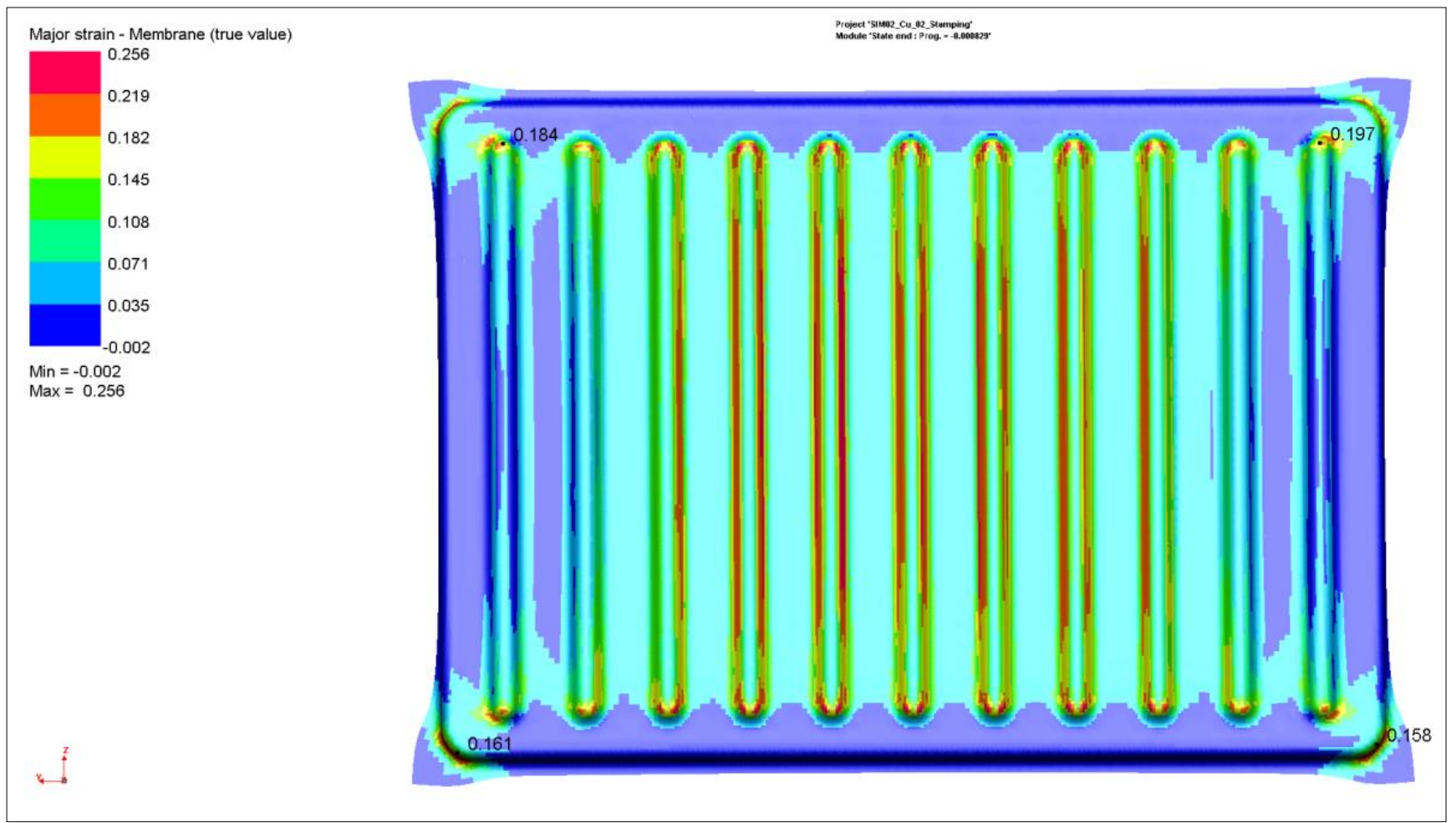

Fig. 5. Main deformations - tested element

In order to select the material for the tool, a compression test of elastomer punches made of available commercial material of various thickness and hardness on the Shore scale was conducted: 70HA, 80HA, 90HA. Ultimately, it was decided to use an elastomer sheet with 80HA hardness. The possibility of forming parts with a selected method was confirmed by numerical simulation (fig. 4) [10].

A map of stresses generated during the pressing process was also obtained. The maximum stress value is 800 MPa. Fig. 5 shows the main deformations obtained at the simulation stage.

There are several ways to mold with a flexible punch. One of them is pressing in two stroke of the slider, i.e. first pressing with the elastomer plate only (incomplete initial pressing), and then pressing by adding an additional flexible plate to the blank to obtain the final shape. Division of molding into stages allows to increase the tool life. Usually, rubber or elastomer spacers with a hardness of $40 \div 50$ by Shore are used for the finishing molding process. The durability of such flexible elements is at the level of $2000 \div 5000$ pieces.

A limitation in the use of the flexible stamping method is the formation of curves with small radii - due to the high concentration of surface pressures in strictly defined small areas. In this case, obtaining the required geometry requires the introduction of a finishing (calibrating) part operation. 


\section{Practical pressing tests}

In order to verify the results obtained in the computer simulation, practical tests were carried out on pressing the tank panels. Blanks made of 1.4301 steel with a thickness of $g=0.5 \mathrm{~mm}$ were used $[3,4]$. The die shown in fig. 6 was designed and manufactured.

The produced model is shown in fig. 7. In the process of pressing with a flexible stamp, a product with geometry that reproduces the assumed CAD model was obtained. Accurate dimensions and shape of embossing were obtained. Sheet metal folds on free surfaces outside the contour of the object [8]. The tests have shown that the occurrence of folds can be reduced using blanks with dimensions appropriately enlarged in relation to the dimensions of the product and by cutting the corners of the blanks. As a result of the pressing process, a product with satisfactory surface condition was obtained.

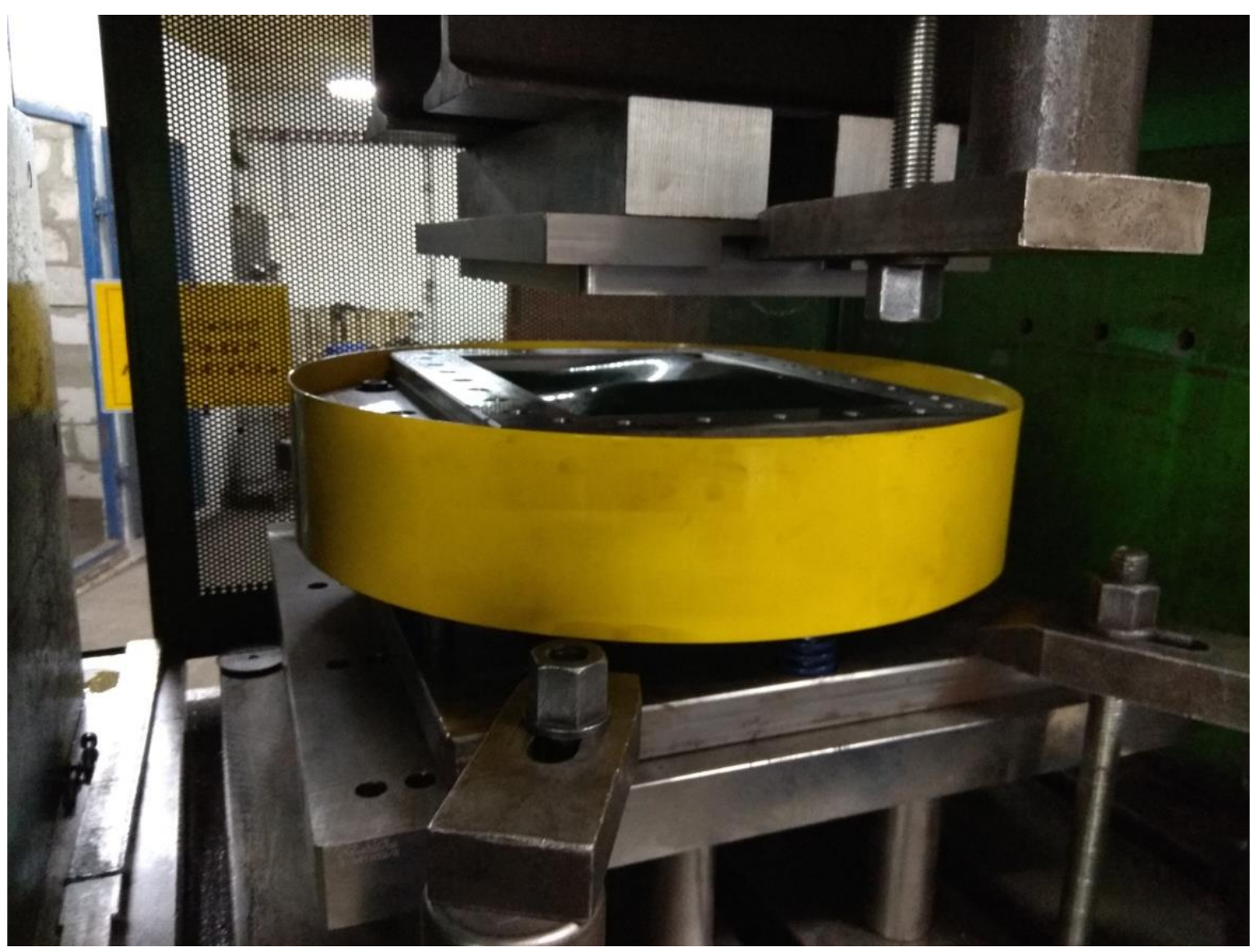

Fig. 6. Die for forming parts with an elastomer tool - view of the die on a hydraulic press

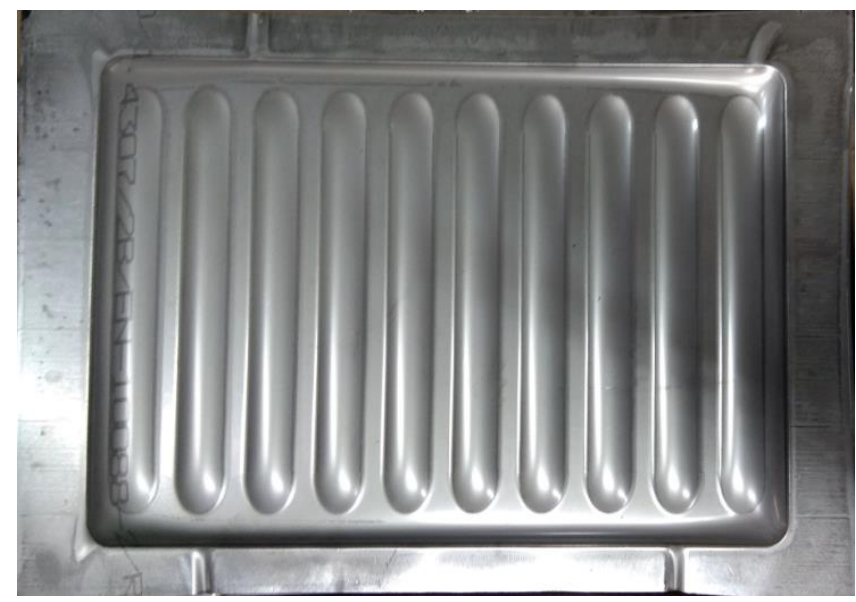

Fig. 7. Tank panel made by flexible stamping 


\section{Conclusions}

The method of forming products with a steel stamp is more advantageous compared to forming with an elastic stamp due to the tool's durability and the use of high material pressure, which allows to avoid creasing the material on the edges of shaped objects. However, forming with a steel punch is much more expensive, because the tool is more complicated and gas springs need to be used, which significantly increases the cost of the tool (by approximately 50\% compared to the tool with an elastomeric punch).

The method of forming with a rubber punch is less efficient and has a shorter tool life, which must be replaced more often. In this method, however, the tool design process is simpler and shorter, which reduces the costs of its implementation. As demonstrated by numerical analysis and practical research, elastomer molding provides the right way to shape the extrusion, therefore, this method is generally more cost-effective and guarantees good product shape at the prototype or small batch stage.

Comparing the molding methods with a rigid matrix and flexible punch, it should be noted that in the latter method, much higher deformation coefficient can be obtained. The conducted tests showed that - taking into account the size of the formed part, sheet thickness and material (chromium-nickel steel) - it is necessary to use a press with relatively high pressure, i.e. above $2000 \mathrm{kN}$. Too low rubber pressure causes local sheet creasing. The intersection of stiffening grooves can be an area of significant weakening of the material.

\section{REFERENCES}

[1] Wagoner R.H., Chenot J.L. "Metal Forming Analysis"(2011): 177-198.

[2] Bałon P., Świątoniowski A., Szostak J. "Improved method of springback compensation in metal forming analysis". Strength of Materials. 48, 4 (2016): 540-550.

[3] Troive L., Bałon P., Świątoniowski A., Mueller T., Kiełbasa B. "Springback compensation for a vehicle’s steel body panel". International Journal of Computer Integrated Manufacturing. 31, 2 (2018): 152-163.

[4] Bałon P., Świątoniowski A., Kiełbasa B. "The analysis of bottom forming process for hybrid heating device". ESAFORM 2017: Proceedings of the $20^{\text {th }}$. International ESAFORM Conference on Material Forming. T. 1896 (2017).

[5] Wie H., Chen W., Gao L. "Sprinback Investigation on Sheet Metal Incremental Formed Parts". 2011.

[6] Seki N. "Successfully controls springback in thin Ultra-High Strength Steel stamping parts using PAMSTAMP 2G". TOA Industries (2011).

[7] Wagoner R.H., Wang J.F., Li M. "Volume 14B: Metalworking: Sheet Forming". ASM Handbook. The Ohio State University, 2006.

[8] Li H., Li G.S.G., Gong Z., Liu D., Li Q. “On twist springback in advanced high-strength steels”. Materials and Design. 32 (2011).

[9] ESI Group PAM-STAMP 2G 2011. “User's Guide”. France, 2011.

[10] Abdullah A.B., Sapuan S.M., Samad Z., Aziz N.A. "A comprehensive review of experimental approaches used in the measurement of springback". Advances in Natural and Applied Sciences. 6, 2 (2012): 195-205. 